\title{
Bees Klebsiellosis: Key Aspects of Pathogenesis
}

\section{Anastasita Lakhman, Olexandr Galatiuk, Tatiana Romanishina*, Vasyl Behas, Olga ZASTULKA}

Polissia National University, Stary Boulevard, 7, Zhytomyr, 10008, Ukraine.

\begin{abstract}
Beekeeping is an important part of the several farming sectors' contemporaneous development in many countries. Bee colonies act not only as food crops' pollinators, but also provide the population with food, medical and vitamin-stimulating agents. Significant factors that hinder the beekeeping development, along with the cumulative effect of other exogenous and endogenous elements, are infectious pathologies. One of such pathologies is bee colonies' Klebsiellosis - a factorial, stationary bacterial disease caused by pathogens belonging to the species Klebsiella Pneumoniae and Klebsiella Aerogenes. Such dysbiosis is characterized by apathy, anorexia, dyspeptic symptom complex, intoxication and high mortality in adult bees and their larvae. The lack of justification for this pathology's development mechanisms became a prerequisite for the formation of bacterial infection's pathogenetic picture, taking into account the peculiarities of the bee organism's physiological and morphological structure. Summarizing the latest achievements in clinical and laboratory studies of this pathology both in humane and veterinary medicine, we interpret the main pathogenetic factors of pathogens' influence on different levels of bee organism's organization - from the midgut's wall morphological composition to self-poisoning of the whole macroorganism. The pathogenetic picture formation of this pathological state can contribute to the therapeutic agents' development in biomedical and veterinary laboratories.
\end{abstract}

Keywords | Apis mellifera, Dysbiosis, Klebsiella, Clinical picture, Pathogenesis.

Received | March 30, 2021; Accepted | April 10, 2021; Published | July 01, 2021

*Correspondence | Tatiana Romanishina, Polissia National University, Stary Boulevard, 7, Zhytomyr, 10008, Ukraine; Email: tveterinar@gmail.com

Citation | Lakman A, Galatiuk O, Romanishina T, Behas V, Zastulka O (2021). Bees klebsiellosis: key aspects of pathogenesis. Adv. Anim. Vet. Sci. 9(8): 1190-

1193.

DOI | http://dx.doi.org/10.17582/journal.aavs/2021/9.8.1190.1193

ISSN (Online) | 2307-8316; ISSN (Print) | 2309-3331

Copyright (C) 2021 Romanishina et al. This is an open access article distributed under the Creative Commons Attribution License, which permits unrestricted use, distribution, and reproduction in any medium, provided the original work is properly cited.

$\mathrm{E}$ ach country has the problem of reliable nation's food provision. Its solving requires the joint efforts of several farming sectors (livestock and crop production), including beekeeping - one of the most developed agricultural sectors in Ukraine.

Ukraine is one of the five countries in the world for the production of bee products. These insects' ecological and economic role is regulated by an increase in the yield of food crops, since plant pollination is one of their most important functions. Apis mellifera is a living organism, which is the most susceptible to the action of such environmental factors as lack of honey bases, the effect of pesticides, ultraviolet and electromagnetic radiation, the de- structive effect of the Varroa mite, bee colonies' low genetic resistance. The action of above factors leads to a decrease in the resistance of the bee organism, behavioral changes in life activity (Glenny et al., 2017). In recent years, there has been observed a decrease in the number of individuals in bee colonies' populations during the wintering period. According to Serdyuchenko (2017), the etiological factor of the bee colonies' immunological instability in different times of year is an imbalance in the ratio of the quantitative and qualitative composition of intestinal bacteria, in other words, insect dysbiosis. (Serdyuchenko, 2017). The intestinal microbiome research is one of the basic studying stages of the root cause for diseases of various etiologies. Thus, the interaction between the host macroorganism and 
microorganisms of different body's nosological structures is poorly studied both in human and veterinary medicine (Kim et al., 2018; Yang et al., 2015; DeGruttola et al., 2016). Bacteria of the genus Klebsiella Pneumoniae and Klebsiella Aerogenes (Enterobacter Aerogenes) are widespread pathogens that can cause polysystemic diseases (klebsiellosis) in humans and animals.

Nowadays the pathogenetic picture's formation of the bees Klebsiellosis development is an urgent problem. The pathological condition mechanisms can be revealed by scientifically substantiating the existing knowledge about pathogenetic manifestations of enterobacteria virulence factors, taking into account the peculiarities of the bee organism's physiological and morphological structure. Monitoring of the studied pathology was statistically analyzed on the basis of official reporting data from regional state laboratories of the State Service of Ukraine for Food Safety and Consumer Protection in the North-West and Central regions of Ukraine. There were recorded the dysbiosis typical clinical signs in spontaneously infected bee colonies at unfavorable apiaries. Laboratory diagnostics of bee Klebsiellosis infections included the isolation of pathogens (Klebsiella Pneumoniae and Klebsiella Aerogenes (Enterobacter Aerogenes)) from insects with clinical disease to special and elective nutrient media for enterobacteria into pure cultures by the Gold method, and their identification by certified and standardized tests (Galatiuk et al., 2020; Romanishina et al., 2020). The bacterial cells' morphological features of typical colonies and the cytochromeoxidase activity (indophenol oxidase) differentiate the Genus of the of the isolated pathogens. The physiological properties of the Klebsiella Pneumoniae and Klebsiella Aerogenes (Enterobacter Aerogenes) rank were established in a sequential series of biochemical typing qualitation (Galatiuk et al., 2020; Romanishina et al., 2020). Our study was approved from the Animal Researches Committee on Bioethics of the Polissia National University.

Information on various animal and human species Klebsiella infections has been interpreted in separate fragments, and in veterinary medicine is limited (Rodrigues et al., 2020). Clinical signs of such bee larvae and bees pathology are similar to the symptom complex of the gastrointestinal tract lesions in human and animal body with nosocomial infections. These clinical signs could be apathy, anorexia, dyspepsia, diarrhea, which leads to body dehydration, loss of the ability to fly, intoxication of larvae (Figure 1). It should be noted that bee larvae pathogens belong to the species Klebsiella Pneumoniae and adult bees patogens are Klebsiella Pneumoniae and Klebsiella Aerogenes (Enterobacter Aerogenes)) (Malek et al., 2019; Paczosa \& Mecsas (2016).

For the scientific interpretation of this pathology

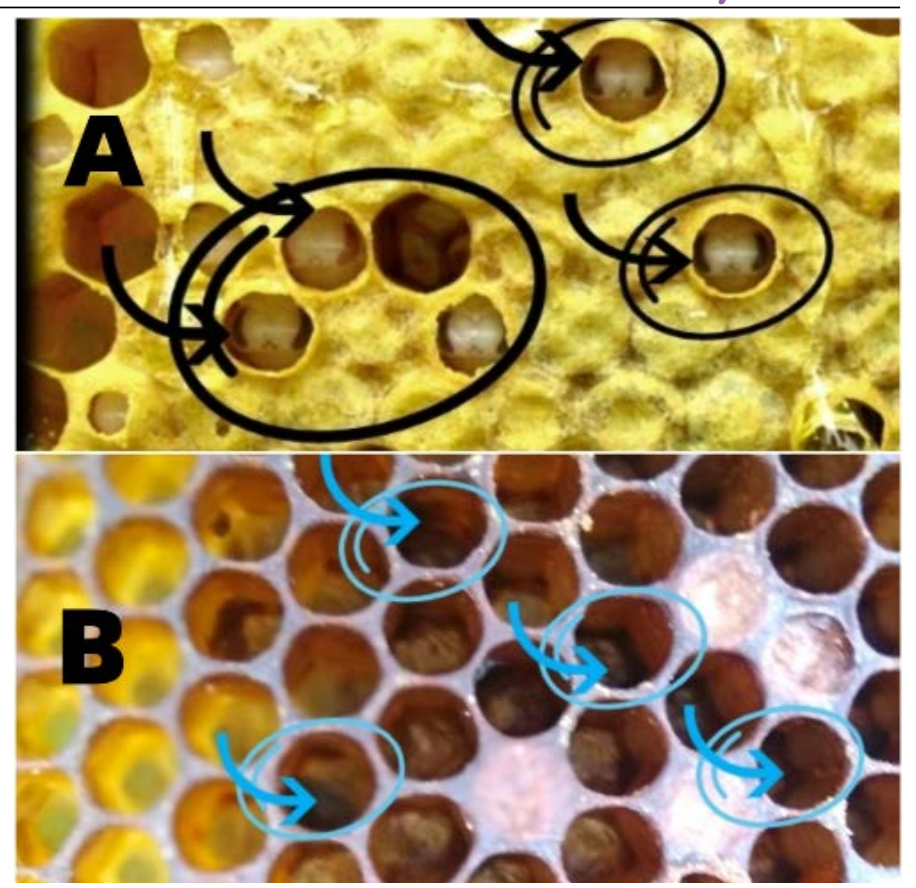

Figure 1: Clinical manifestation of bee klebsiellosis (A - the larva is affected by bacteria of the species Klebsiella Pneumoniae; B - traces of fecal diarrhea in larvae infected with bacteria of Klebsiella Pneumoniae and Klebsiella Aerogenes species

manifestation mechanisms and the study of pathogens toxigenic effect on the host's macroorganism, it is necessary to be aware of its most important organs structure. Histologic study showed that bee's intestinal wall consists of muscle bundles of transverse muscle symplasts (Kovalsky and Kirillov, 2013), that provide peristaltic movements (Rozhenkov et al., 2017) and mucous membranes. The latter form enterocytes which are responsible for the parietal digestion stimulation due to the work of microvils at the apical pole of cells (Kovalsky and Kirillov, 2013). On the inner side of the mucous layer is the basal membrane, the basis of which is chitin. Chitin contributes to the elastic skeleton formation of the insect's stomach, performing a support-trophic function (Rozhenkov et al., 2017). Furthermore, the intestinal mucosa cells are enveloped by a layer of a special peritrophic membrane (Kovalsky and Kirillov, 2013). This membrane's density is provided by proteins and chitin. The peritrophic membrane directly determines the bee's immune status, influencing the possibility of infectious agents' penetration into the hemolymph. It is the presence of basal and peritrophic membranes that is a significant difference in the structure of the mammals' and insects' small intestinal wall.

They provide selective permeability of digested nutrients in the form of simple compounds to the enterocyte cells of the intestinal mucosa, thereby differentiating high molecular weight particles until they are completely processed by the digestive enzymes of the insect's midgut. Therefore, 
an important pathogenetic link in the development of bees Klebsiellosis is the processes of morphological and functional composition disorder in insect's intestinal cells caused by the action of exo- and endoctoxins bacteria of the species Klebsiella Pneumoniae and Klebsiella Aerogenes. Under the influence of favourable factors (Figure 2 - 1), the above conditionally pathogenic microorganisms, acquiring pathogenicity, activate highly virulent polysomal genetic structures. The latter proliferate actively and cause intoxication and immunosuppressive effects on a macroorganism (Paczosa and Mecsas, 2016). The mass abandonment of hives by enterobacteria-infected bees is one of the reasons for «bee colonies collapse» in Ukraine (Galatyuk et al., 2020; Romanishina et al., 2020).

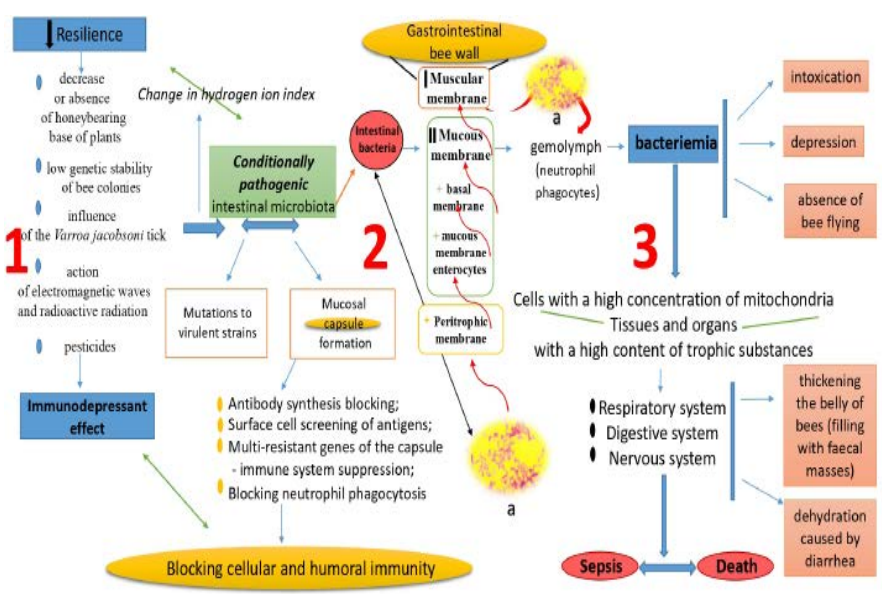

Figure 2: Pathogenesis of bee klebsiellosis (1 - factors of immunosuppressive effect on the bees; 2 - Infiltration of gram-negative bacteria (a) Klebsiella Rneumoniae and Klebsiella Aerogenes (Enterobacter Aerogenes) in morphological and functional elements of intestinal wall of the bees; 3 - terminal link of klebsiellosis of bees)

Some strains of Klebsiella pneumoniae contain genetic elements that make it possible to synthesize yersiniabactin molecules. These molecules are iron assimilable, thus increasing the potential to cause disease (Lam et al., 2018). Therefore, with the uncontrolled generation of these bacteria along with the presence of such genetic elements in them, microorganisms acquire the ability to absorb trace elements of the host organism, causing a a deficiency state. A wide range of bacterial virulence factors Klebsiella Pneumoniae (Capsule Lipopolysaccharide, Type 1 and 3 Fimbriae, Siderophores, OMPs, Porins, Pumps and Transporters, Allantoin Metabolism) allows to show a polyvector effect on bee's physiological state (Paczosa and Mecsas, 2016). In systemic infection, the capsule's presence is a very important fragment for Klebsiella Pneumoniae progression (Tan et al., 2020). Some strains are able to produce a hypermucosal capsule, which consists of a mucous-viscous exopolysaccharide coating. The capsule significantly promotes to this microorganism's pathogenicity (Paczosa and Mecsas, 2016). The above capsule provides the protective bacterium's ability to actively migrate host hemolymph, avoiding immunocompetent cells. This natural hypermucosal layer blocks antibody synthesis, shields antigen surface cells and blocks neutrophil phagocytosis (Tan et al., 2020). Outer membrane protein (OMPs) of Klebsiella Aerogenes (Enterobacter Aerogenes) microorganisms play an important role in ensuring antibiotic resistance and bacterial virulence, which affects the bacterium pathogenicity (Mishra et al., 2020). Pathogenic strains of Klebsiella Aerogenes (Enterobacter Aerogenes) highly invasive and, having adhesive properties, show a high reactivity to the release of oxygen in the neutrophils of hemolymph. On top of that, OMPs are receptors for hemolysin and bacteriocins (Mishra et al., 2020). Thus, the combined virulence factors' effect of enterobacteria species Klebsiella Pneumoniae and Klebsiella Aerogenes (Enterobacter Aerogenes) determine an immunosuppressive effect at the cellular and humoral levels of the bee's body (Figure 2 - 2). The uncontrolled reproduction of these opportunistic microorganisms disrupts the water-electrolyte balance of the bee intestine and reduces the hydrogen ions concentration. Acid balance in the midgut cavity of insects is provided by a constant symbiotic interaction of various species non-pathogenic microorganisms (Serdyuchenko, 2017). When the equilibrium is shifted in any direction, the microorganisms growth is transformed into a competing-displacing type. It happens due to the highly virulent strains accumulation of the dominant concentration (Klebsiella Pneumoniae). Acid metabolites of Genus Klebsiella pathogenic microorganisms come into contact with the peritrophic membrane proteins. Together they form free amino acid groups, which actively interact with membrane chitin polysaccharides during a hyperthermic inflammatory process (enteritis). This ultimately determines its porosity (Figure $2-2$ ). The pathogenetic process is accompanied by the release and accumulation of gases, in particular methane $\left(\mathrm{CH}_{4}\right)$ and ammonia $\left(\mathrm{NH}_{3}\right)$, which increase the osmotic pressure in the insect's midgut. This in turn causes diarrhea, which leads to its body dehydration. Open "gates of infection» cause the pathogenic agents' penetration into the mucosal layer of the intestinal wall. Pathogenic agents destroy the villi and subsequently the mucous membrane enterocytes. Bacterial exotoxins soften the basal membrane chitin by breaking down polysaccharides into di- and oligocharides. Thus, the supporting chitin function is interrupted, the intestine loses its stable position due to the weakening of the mechanical framework. The striated muscle symplasts lose their ability to contract. Therefore, the bee organism's metabolic products are not excreted. They fill the abdomen, thereby blocking the ability to fly. Bacteremia is the last link in the pathogenesis of bee Klebsiellosis. The Klebsiella Pneumoniae and Klebsiella Aerogenes (Enterobacter Aero- 
genes) bacteria cause an energy deficit in highly specialized cells of the macroorganism's nervous, respiratory and digestive systems. Further intoxication causes septicaemia and bees' death (Figure $2-3$ ).

The pathogenetic mechanisms' correlation of Klebsiellosis in bees and mammals is stipulated by the vectors of Klebsiella Pneumoniae and Klebsiella Aerogenes (Enterobacter Aerogenes) pathogenic influence on the intestine's structural and morphological components.

To differentiate the bacteria strains of the Klebsiella Genus in bees and other taxonomic units, it is advisable to identify species related genetic sequences in the polymerase chain reaction.

Summarizing the above, we can make certain conclusions. Bees Klebsiellosis is caused by virulent bacteria strains of the Klebsiella Pneumoniae and Klebsiella Aerogenes (Enterobacter Aerogenes) species. This is a stationary infectious factorial disease characterized by bee's body dehydration, intoxication and sepsis. The disease has a pronounced seasonality (winter-spring period), high mortality (70-85\%) and leads to high economic losses.

\section{CONFLICT OF INTEREST}

There is no conflict of interest.

\section{REFERENCES}

- DeGruttola AK, Low D, Mizoguchi A, Mizoguchi E (2016). Current understanding of dysbiosis in disease in human and animal models. Inf. Bowel Dis., 22(5): 1137-1150. https:// dx.doi.org/10.1097/mib.0000000000000750

- Galatiuk O, Romanishina T, Lakhman A, Zastulka O, Balkanska $\mathrm{R}$ (2020). Isolation and identification of Klebsiella aerogenes from bee colonies in bee dysbiosis. The Thai J. Vet. Med., 50(3): 353-361. https://he01.tci-thaijo.org/index.php/tjvm/ article/view/245844

- Glenny W, Cavigli I, Daughenbaugh KF, Radford R, Kegley SE, Flenniken ML (2017). Honey bee (Apis mellifera) colony health and pathogen composition in migratory beekeeping operations involved in California almond pollination. PloS one. 12(8). https://doi.org/10.1371/journal.pone.0182814

- Kim E, Seo J, Yang SH, Kim IS, Koo Y (2018). Intestine bacterial microbiota of Asian hornet (Vespa velutina nigrithorax) and honey bee. Kor. J. Env. Agricult., 37 (2): 135-140. https:// doi.org/10.5338/KJEA.2018.37.2.18

-Kowalski YuV, Kirillov JI (2013). Morfolohichni osoblyvosti budovy seredn'oyi kyshky u medonosnykh robochykh bdzhil [Morphological features of the structure of the midgut in honey worker bees]. Sci. Mes. of LNU of Vet. Med. Biotech. Ser.: Vet. Sci., 15(3): 114-119 (in Ukrainian).

-Lam MM, Wick RR, Wyres KL, Gorrie CL, Judd LM, Jenney AW, Brisse S, Holt KE (2018). Genetic diversity, mobilisation and spread of the yersiniabactin-encoding mobile element ICEKp in Klebsiella pneumoniae populations. Microb. Genom. 4(9): https://doi.org/10.1099/mgen.0.000196

- Malek A, McGlynn K, Taffner S, Fine L, Tesini B, Wang J, Mostafa H, Petry S, Perkins A, Graman P, Hardy D, Peco N, Pecora N (2019). Next-generation-sequencingbased hospital outbreak investigation yields insight into Klebsiella aerogenes population structure and determinants of carbapenem resistance and pathogenicity. Antimicrob. Agents Chemotherap. 63(6). https://doi.org/10.1128/ AAC.02577-18

- Mishra M, Panda S, Barik S, Sarkar A, Singh DV, Mohapatra H (2020). Antibiotic resistance profile, outer membrane proteins, virulence factors and genome sequence analysis reveal clinical isolates of Enterobacter are potential pathogens compared to environmental isolates. Front. Cel. Inf. Microb., 10, 54. https://doi.org/10.3389/fcimb.2020.00054

- Paczosa MK, Mecsas J (2016). Klebsiella pneumoniae: going on the offense with a strong defense. Microb. Mol. Biol. Rev., 80(3): 629-661. https://doi.org/10.1128/MMBR.00078-15

- Rodrigues MX, Yang Y, de Souza Meira JrE, Silva JC, Bicalho RC (2020). Development and evaluation of a new recombinant protein vaccine (YidR) against Klebsiella pneumoniae infection. Vaccine. 38(29): 4640-4648. https:// doi.org/10.1016/j.vaccine.2020.03.057

- Romanishina TA, Galatiuk OYe, Lakhman AR, Behas VL, Andriichuk AM, Solodka LA (2020). Application of biochemical typing in veterinary medicine in bee enterobacterioses to determine Klebsiella Pneumoniae. Sci. Mes. of LNU of Vet. Med. and Biotech. Ser.: Vet. Sci., 22(99): 101-106 (in Ukrainian). https://doi.org/ 10.32718/ nvlvet9916

- Rozhenkov AS, Delaev UA, Baitaev MO (2017). Stroyeniye I funktsionirovaniye zheludka medonosnoy pchely [Structure and functioning of the honey of the honey bee]. In: Modern problems of beekeeping, Grozny, pp. 192-195 (in Russian).

-Serdyuchenko IV (2017). Quantitative evaluation of the digestive tract microflora of the bees before and after wintering. Sci. Heritage, 39(1): 286-289 (in Russian).

-Tan YH, Chen Y, Chu WH, Sham LT, Gan YH (2020). Cell envelope defects of different capsule-null mutants in $\mathrm{K} 1$ hypervirulent Klebsiella pneumoniae can affect bacterial pathogenesis. Mol. Microb., 113 (5): 889-905. https://doi. org/10.1111/mmi.14447

- YangT, Santisteban MM, Rodriguez V, Li E, Ahmari N, Carvajal JM, Zadeh M, Gong M, Qi Y, Zubcevic J, Sahay B, Pepine CJ, Raizada MK, Mohamadzadeh M (2015). Gut dysbiosis is linked to hypertension. Hypertension. 65(6): 1331-1340. https://doi.org/10.1161/Hypertensionaha.115.05315 